\title{
Metabolomic profiling of serum in aging mice supplemented with tocotrienol-rich fraction for identification of female reproductive aging biomarkers
}

\author{
Norrabiátul Adawiyah Aziz a, Fathimah Mohamad b, Teh Lay Kek c, Nuraliza Abdul Satar b,* \\ a Institute of Medical and Molecular Biotechnology (IMMB), Faculty of Medicine, Universiti Teknologi MARA, Sungai Buloh, Selangor, Malaysia \\ b Faculty of Medicine, Universiti Teknologi MARA, Sungai Buloh, Selangor, Malaysia \\ c Integrative Pharmacogenomics Institute (iPROMISE, Faculty of Pharmacy, Universiti Teknologi MARA, Puncak Alam, Selangor, Malaysia
}

*Corresponding author: nuraliza064@salam.uitm.edu.my

\section{Article history}

Received 20 Mac 2018

Revised 5 April 2018

Accepted 8 May 2018

Published Online 16 December 2018

\begin{abstract}
Ovarian aging has been associated with increased oxidative stress leading to loss of ovarian function and infertility. Tocotrienol, a potent antioxidant, has been proven to exert beneficial effects in the female reproductive system. Serum metabolites were analyzed to examine the biochemical changes and to identify biomarkers related to reproductive aging that could lead to poor embryo quality and development. Female Mus musculus mice were divided into four groups. Six-month-old mice were given tocopherol-stripped corn oil as a vehicle control while other groups were supplemented orally with the tocotrienol-rich fraction (TRF) at doses of 90,120 , and $150 \mathrm{mg} / \mathrm{kg}$ body weight for two months, respectively. After two months, mice from all groups were superovulated and euthanized. Embryos were collected at the 2-cell stage and cultured to monitor their development while serum was used for metabolomic analysis. The percentage of normal embryos and development of embryos to blastocyst stage were significantly higher in groups supplemented with TRF. A total of 71 metabolites that are related to reproductive aging were identified in all groups and significant changes were detected in metabolic pathways that include fatty acids, amino acids metabolism and steroid hormone biosynthesis. These changes suggest that aging has a negative impact on cellular energy storage, energy metabolism and oxidative stress that subsequently affect female fertility. Supplementation with TRF prevented the impact of age-related metabolic changes on the embryo. Thus, it appears that TRF exerts a protective mechanism towards female reproductive aging.
\end{abstract}

Keywords: Ovarian aging, tocotrienol, metabolomics, embryo

\section{INTRODUCTION}

In general, one in every four couples in developing countries is affected with fertility issues (Mascarenhas et al., 2012). Fertility in female declines in parallel with aging. Factors such as an increase in education levels, a more active working life and easier contraceptive methods have caused many women to delay childbearing (Sukur et al., 2014). As a result, these women may possibly experience a loss in ovarian function and may even lose their fecundity. Consequently, during aging, an imbalance between reactive oxygen species (ROS) and antioxidant systems occur leading to oxidative stress and later negatively impacting reproductive processes such as ovulation, fertilization and embryonic development (Agarwal et al., 2005).

In contrast, supplementation with antioxidants that can counteract oxidative stress could potentially help in reducing the damage caused by the aging process (Liu et al., 2012). Tocotrienol is known to possess antioxidant properties and was scientifically proven to exert beneficial effects on the female reproductive system. To date, several studies have demonstrated that tocotrienol supplementation improves the quality of embryos and embryonic development (Kamsani et al., 2013; Shahidee et al., 2013) and preserves ovarian function (Saleh et al., 2015) following exposure to oxidative stress.

A complete overview of metabolic changes related to the reproductive system in healthy aging mammals remains lacking. Hence, serum metabolites have been used to understand the biochemical changes that take place during aging and to identify agerelated biomarkers and metabolites that are related to reproductive aging. Therefore, this study performs a metabolomics analysis of aging mice supplemented with TRF to identify the metabolites involved in female reproductive aging and infertility and to elucidate pathways which promote antioxidant mechanism.

\section{EXPERIMENTAL}

\section{Materials}

Chemicals used in this study were purchased from the indicated sources: Tocopherol-stripped corn oil (MP Biomedicals, USA) and tocotrienol-rich fraction palm oil (Sime Darby Biorganic Sdn. Bhd., Malaysia). Tocotrienol-rich fraction palm oil per $100 \mathrm{~g}$ contained: $\alpha$ - 
tocotrienol $(27.3 \%), \beta$-tocotrienol $(3.3 \%), \gamma$ - tocotrienol $(35.5 \%), \delta$ tocotrienol (10.4\%) and $\alpha$-tocopherol (23.4\%). Tocotrienol was diluted with tocopherol-stripped corn oil (Mokhtar et al., 2008) to obtain the desired concentration of 90,120 and $150 \mathrm{mg} / \mathrm{kg}$ body weight.

\section{Mice feeding, mating and tocotrienol supplementation}

The experimental protocol was in strict accordance with the regulations and prescribed animal ethical procedures outlined by the Research Committee on the Ethical Use of Animals (UiTM Care: 159/2016). In this study, female Mus musculus mice aged 1) six weeks old (young) with an average body weight of $14.8-19.7 \mathrm{~g}$ and 2) six months old (aging) with an average body weight of $26-30 \mathrm{~g}$ were used for experiments. The animals were housed at $27^{\circ} \mathrm{C}$ under 12 -hour lightdark cycles. The mice were given food pellets and water ad libitum daily. The mice were divided into two main groups, control groups and experimental group. For each group, eight mice were used $(n=8)$. Mice at the age of 6 weeks (young group) were used as a negative control group, while mice at the age of 6 months were used as a positive control group. The control group were given $0.1 \mathrm{ml}$ tocopherol-stripped corn oil as a vehicle for two months. In the experimental group, mice aged 6 months were supplemented daily using the force-feeding technique (oral gavage) for 2 months with $0.1 \mathrm{ml}$ TRF at a dose of 90,120 or 150 $\mathrm{mg} / \mathrm{kg} \mathrm{BW}$. The TRF doses used in this study is the optimum dosage obtained from previous studies on the effect of TRF supplementation in aging mice on the quality of embryo (Saidatul et al., 2014; Norerlyda et al., 2015).

After 2 months, all mice from aging (positive control), vehicle control and TRF supplemented groups were superovulated by intraperitoneal (ip) injection of $0.1 \mathrm{ml} 5$ IU pregnant mare serum gonadotropin (PMSG), followed by $0.1 \mathrm{ml}$ human chorionic gonadotropin (hCG) 48 hours later, and mated with the fertile male mice at a ratio 1:1 (Nagy et al., 2003). The mice then were anaesthetized with $0.1 \mathrm{ml}$ per mice using ketamine, zoletil and xylazine solutions mixed with distilled water and blood were collected via cardiac puncture. Following that, mice were euthanized to excise the oviducts and then were proceeded with flushing of the embryo.

\section{Embryo collection}

The mouse was superovulated by given intraperitoneal (ip) injection of 5 IU PMSG, followed by 5 IU hCG 48 hours later and mated with fertile male mice at ratio 1:1. After the blood collection, superovulated female mice that were successfully mated were euthanized 48 hours after hCG injection, and embryos were collected. Both oviducts were excised and embryos were flushed out under a dissecting microscope and the numbers of normal and abnormal embryos were counted and recorded.

\section{In vitro development of embryos}

Embryos were cultured in a 35-mm culture dish filled with $100 \mu \mathrm{l}$ droplets of Whitten's medium overlaid with mineral oil. The cultures were maintained in a humidified atmosphere incubator containing 5\% $\mathrm{CO}_{2}$ and $90 \%$ air at $37^{\circ} \mathrm{C}$ for 6 days. Assessment of embryonic development and cleavage were made under an inverted microscope (Leica DM IRB) every 20-24 hours and number of blastocysts were observed and counted (Nagy et al., 2003).

\section{Blood collection and preparation of serum for differential expression of metabolomics profiles}

Blood samples were collected via cardiac puncture after the mice were anaesthetized with $0.1 \mathrm{ml}$ per mice using ketamine, zoletil and xylazine solutions mixed with distilled water (Nagy et al., 2003). Serum then was separated by centrifugation $\left(3000 \mathrm{rpm}, 4^{\circ} \mathrm{C}\right.$ for 15 minutes) and frozen at $-80^{\circ} \mathrm{C}$ until analysis. All samples were subjected to liquid-liquid extraction of cold acetonitrile and pure water in an icecold condition.
To remove residual protein that would otherwise affect retention time, reproducibility and lead to detection interference in LC/MS, a total of $450 \mu \mathrm{l}$ of acetonitrile/deionized water (2:1) were added into 150 $\mu \mathrm{l}$ of serum sample for protein precipitation in a $1.5 \mathrm{ml}$ microcentrifuge tube, then vortexed briefly for 15 seconds and centrifuged at $10,000 \times \mathrm{g}$ for 10 minutes at $4^{\circ} \mathrm{C}$. The supernatant was transferred into a new tube and $300 \mu \mathrm{l}$ of acetonitrile was added for a second protein precipitation process. The supernatant was dried using vacuum concentrator before being reconstituted with the mobile phase and injected to the liquid chromatography/mass spectrometry quadrupole-time of flight (LC/MS Q-TOF).

\section{LC/MS Q-TOF analysis}

Chromatography, separation and detection of small molecules were performed by Liquid Chromatography of 1200 Rapid Resolution Series, composed of a binary pump, degasser, well plate autosampler with thermostat, thermostat column compartment and 6520 Q-TOF mass spectrometer equipped with a dual-ESI source. Zobrax Eclipse Plus C18 - ID of $1.8 \mu \mathrm{m}$ particle size and $2.1 \times 100 \mathrm{~mm}$ column dimensions were used. The temperature was maintained at $40^{\circ} \mathrm{C}$ during the run. The mobile phase composed of (A) $0.1 \%$ formic acid in water and (B) $0.1 \%$ formic acid in acetonitrile. The flow rate was set at 0.25 $\mathrm{ml} / \mathrm{min}$ and the injection volume was $2 \mu \mathrm{l}$. A linear gradient was developed over 36 minutes from 5\% to $95 \%$ of the mobile phase (B). The total run time was set at 48 minutes for each analysis. ESI Source settings were as follows: V Cap $4000 \mathrm{~V}$, skimmer $65 \mathrm{~V}$ and fragmentor $125 \mathrm{~V}$. Mass spectral acquisition range was set from 50 to $1400 \mathrm{~m} / \mathrm{z}$. The nebulizer was set at 45 psig and the nitrogen drying gas was set at a flow rate of $12 \mathrm{~L} / \mathrm{min}$. Drying gas temperature was maintained at $350^{\circ} \mathrm{C}$. Data were acquired at a rate of $2.5 \mathrm{spectra} / \mathrm{second}$ with a stored mass range of $\mathrm{m} / \mathrm{z} 50-1000$. Internal reference ions and were used to correct mass accuracy. Auto calibration parameters were chosen to average 5 scans and reference mass correction was enabled throughout the run. The mass spectrometer was tuned to allow detection of compounds to the accuracy of $\pm 2 \mathrm{ppm}$ before the analysis. Internal reference ions (m/z 121.0509 and 922.0098) were used to correct mass accuracy throughout the run.

\section{Data processing and statistical analysis}

For embryonic quality and development, the data were analyzed using Statistical Package for Social Science (SPSS) version 25 and data were expressed as a percentage. The significant differences between groups were analyzed using the Chi-Square Test and considered significant at $\mathrm{p}<0.05$.

For metabolite profiling, MassHunter Workstation software, including Qualitative Analysis (version 3.01) and Mass Profiler Professional (version B.02.00) were used for processing raw data including data mining, data filtering, and statistical analysis. To minimize the number of missing values, only metabolites that were consistently detected in at least $50 \%$ of samples were included in the statistical analyses. All known artifact peaks, such as internal standards, column bleed, plasticizers or reagent peaks were excluded from the result sheets. All metabolite data were normalized relative to the sum of all known metabolites in each sample and were log transformed. The identified metabolites later then were checked on their associated pathway in the Kyoto Encyclopedia of Genes and Genomes (KEGG) database.

\section{RESULTS AND DISCUSSION}

The aging process may result in ovarian failure and this may lead to a decrease in the number of follicles, loss of follicular functions, a decline in oocyte reserve as well as embryo quantity, quality and its development (Sukur et al., 2014). In this study, the quality of embryos 


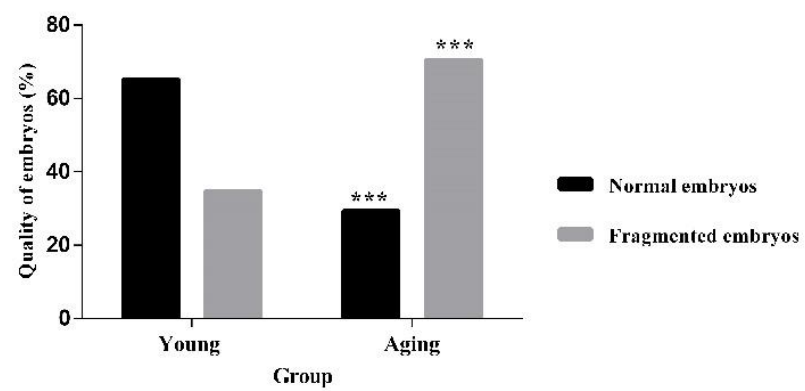

Fig. 1 Embryo quality in young and aging mice.

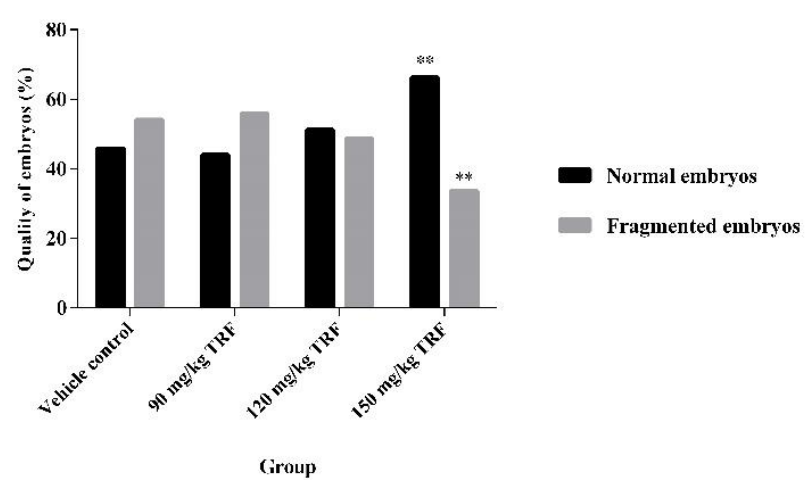

Fig. 2 The effect of TRF supplementation on the quality of embryos in aging mice.

The embryonic development was validated based on the observation of embryos from 2-cells until they reached the blastocyst stage. From the observation, the percentage of embryos that reached the blastocyst stage in the aging group was significantly lower $(\mathrm{p}<0.001)$ (Table 1) while in group supplemented with $150 \mathrm{mg} / \mathrm{kg}$ TRF, the percentage of embryos that reached blastocyst stage was improved $(\mathrm{p}<0.01)$ and development restored towards normal (Table 2). This finding indicates that oxidative stress-induced ovarian aging results in the dysfunction of the reproductive process (Fujii et al., 2005). As a consequence, the arrested embryos were not able to develop to blastocyst, which affects the implantation process thus leading to infertility (Danilovich \& Sairam, 2005).

Table 1 Embryonic development in aging mice.

\begin{tabular}{|l|c|c|c|c|c|c|}
\hline & \multicolumn{7}{c|}{ Embryonic Developmental Stages (\%) } \\
\hline Group & 2 cells & 4 cells & 8 cells & 16 cells & Morula & Blastocyst \\
\hline Young & 100 & 100 & 93.3 & 85.3 & 80 & 77.3 \\
\hline Aging & 100 & $88^{* *}$ & $64 * * *$ & $48^{* * *}$ & $40^{* * *}$ & $36^{* * * *}$ \\
\hline
\end{tabular}

Table 2 The effect of TRF supplementation on the embryonic development in aging mice.

\begin{tabular}{|l|c|c|c|c|c|c|}
\hline \multirow{2}{*}{ Group } & 2 cells & 4 cells & 8 cells & 16 cells & Morula & Blastocyst \\
\hline Vehicle control & 100 & 92.6 & 88.2 & 80.9 & 70.6 & 44.1 \\
\hline $\mathbf{9 0} \mathbf{~ m g / k g ~ T R F ~}$ & 100 & 90.9 & 90.9 & 75.8 & 54.5 & 30.3 \\
\hline $\begin{array}{l}\mathbf{1 2 0} \mathbf{~ m g / k g} \\
\text { TRF }\end{array}$ & 100 & 95.1 & 95.1 & 85.1 & 73.2 & 36.6 \\
\hline $\begin{array}{l}\mathbf{1 5 0} \mathbf{~ m g / k g} \\
\text { TRF }\end{array}$ & 100 & $100^{*}$ & $100^{* *}$ & 87.3 & 76.2 & $63.5^{* * *}$ \\
\hline
\end{tabular}

Based on the results of embryo quality and development, 150 $\mathrm{mg} / \mathrm{kg} \mathrm{BW}$ was selected as the optimum dose of TRF supplementation and this dose was used in the subsequent study to identify metabolites involved in female reproductive aging and infertility. Metabolomics has been widely used to identify biomarkers and to build metabolic profiles associated with biological activities and physiological status (Ke et al., 2015). In metabolomics analysis, it was shown that metabolic dysfunction is a common hallmark of the aging process. In this study, profiling and screening of all available metabolites that might be related to female reproductive system and aging were done. Differences of metabolites regulation presented in fold change in young, aging, vehicle control and $150 \mathrm{mg} / \mathrm{kg}$ TRF groups was presented in Fig. 3. The metabolites were down-regulated in young group and some metabolites in the group supplemented with $150 \mathrm{mg} / \mathrm{kg}$ TRF were less regulated as compared to the other aging groups.

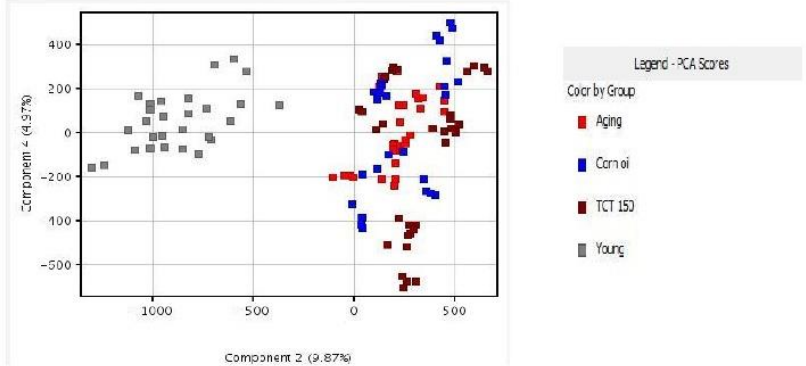

Fig. 3 PCA scatter plot showing the differentiation of metabolites regulation (fold change) in Young, Aging, Vehicle control and $150 \mathrm{mg} / \mathrm{kg}$ TRF groups.

In samples from four groups (young, aging, vehicle control and TRF $150 \mathrm{mg} / \mathrm{kg} \mathrm{BW}$ ), approximately 71 metabolites from 1049 metabolites related to reproductive aging were identified (Fig. 4).

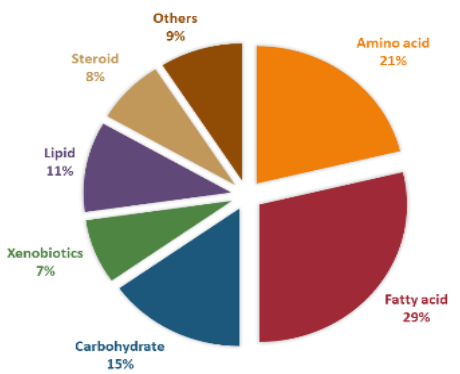

Fig. 4 Class distribution of identified metabolites.

The most remarkable changes in metabolites among all groups were defined by a significant increase in lipid-related metabolites in the aging group and a decrease in the TRF-supplemented group, including lysophosphatidylcholine, phosphocholine, and fatty acids (Fig 5). Previously it was reported that in aging, as an alternative for oxidative phosphorylation, fatty acid was utilized for ATP production (Fong et al., 2011). Accumulation of fatty acids intermediates in the cardiomyocyte cytosol could result in lipotoxicity and could result in a decrease in fertility (Wu et al., 2010).

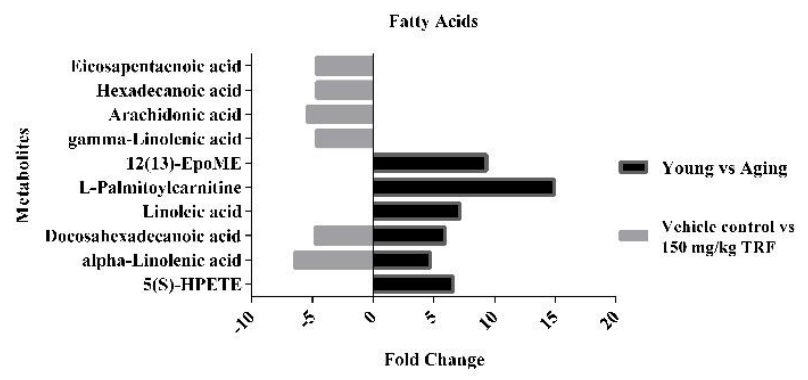

Fig. 5 Differences in the regulation of fatty acids metabolites.

An increased concentration of most amino acids in serum metabolite of an aging group that was found in this study (Fig. 6) could result from an increase in the rate of a whole-body protein breakdown, insulin resistance and subsequent oxidation of their carbon skeletons in the citric acid cycle (Lawton et al., 2008). However, a significant downregulation in amino acids metabolism was observed in the TRFsupplemented group. This finding is comparable to a report by Botros et al. (2008), which found that embryos with greater viability have a lower or quieter amino acid metabolism which is needed for successful implantation than those that was arrested. Although the effect of serum amino acids on ovarian function and aging is still not well understood, 
a recent study on metabolic profiles of ovarian follicular fluid collected from patients undergoing in vitro fertilization (IVF) revealed women with repeated IVF failure had increased concentrations of amino acids (Xia et al., 2014). Interestingly, the process was reversed in the TRFsupplemented group by downregulating the amino acid metabolism, thus suggesting the effectiveness of TRF in combating oxidative stress and enhancing antioxidant defense mechanisms. This was in accordance with the finding of Khor et al. (2017), where they found similar outcomes in senescent human myoblast tissue supplemented with TRF.

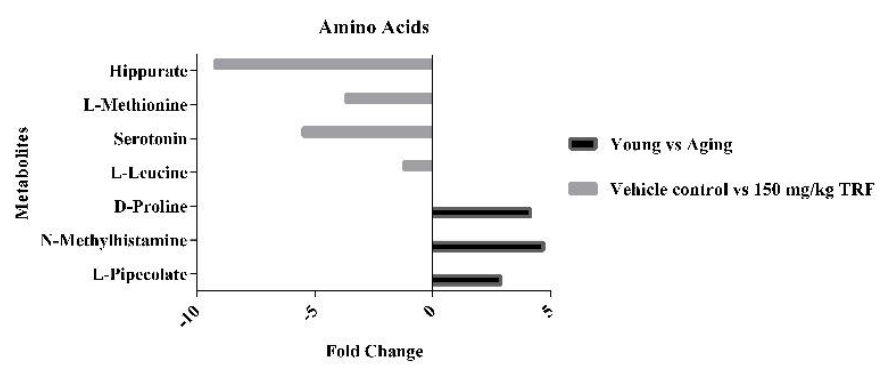

Fig. 6 Differences in regulation of amino acids metabolites.

These findings also suggest that a few pathways are useful in analyzing the effect of aging on female reproductive systems. Steroid hormone biosynthesis shows a significant increase $(p<0.001)$ in the aging group as compared to the young group. Interferences with steroid biosynthesis may result in impaired reproduction, hormonal disruption, and cellular regulation (Sanderson, 2006). Interestingly, in TRFsupplemented group, steroid hormone biosynthesis was significantly decreased $(\mathrm{p}<0.01)$, suggesting that tocotrienol is potent in blocking the secretion of corticosterone in stressed rats (Nur Azlina et al., 2008) and improves the quality of embryo, in vitro embryonic development and pregnancy outcomes in mice exposed to corticosterone inducedoxidative stress conditions (Nasibah et al., 2012).

\section{CONCLUSION}

In summary, TRF supplementation at a dose of $150 \mathrm{mg} / \mathrm{kg}$ for two months was effective in overcoming the adverse effect of oxidative stress and perhaps might delay the consequences of reproductive aging. This study also shows that supplementation of TRF was beneficial in maintaining fertility by exerting its effect on the quality and development of embryos derived from aging mice. Some metabolites that were identified proved to be involved in ovarian aging. Subsequently, changes in these metabolites that can act as female reproductive aging biomarkers were detected following TRF supplementation. The pathways that were identified also suggest a positive relationship between metabolomic changes in serum and the quality of embryo in aging mice supplemented with TRF.

\section{ACKNOWLEDGEMENT}

This study was financially supported by the Research Acculturation Grant Scheme (RAGS) (600-IRMI/RAGS 5/3 (43/2014)) and Geran Insentif Penyeliaan (600-IRMI/MyRA 5/3/GIP (071/2017)). The authors gratefully acknowledge the facilities provided by Laboratory Animal Care Unit (LACU), UiTM Sg Buloh, Institute of Medical Molecular Biotechnology (IMMB), UiTM Sg Buloh and Integrative Pharmacogenomics Institute (iPROMISE). This research was under the Cellular Stress Dynamics Research Interest Group (RIG).

\section{REFERENCES}

Agarwal, A., Gupta, S., Sharma, R. K. (2005). Role of oxidative stress in female reproduction. Reproductive Biology and Endocrinology: RB\&E, 3, 28.

Botros, L., Sakkas, D., Seli, E. (2008). Metabolomics and its application for noninvasive embryo assessment in IVF. Molecular Human Reproduction, 14(12), 679-690.
Danilovich, N., Ram Sairam, M. (2006). Recent female mouse models displaying advanced reproductive aging. Experimental Gerontology, 41(2), $117-122$.

Fong, M., McDunn, J., Kakar, S. S. (2011). Identification of metabolites in the normal ovary and their transformation in primary and metastatic ovarian cancer. PLOS ONE, 6(5), 1-12.

Fujii, J., Iuchi, Y., Okada, F. (2005). Fundamental roles of reactive oxygen species and protective mechanisms in the female reproductive system. Reproductive Biology and Endocrinology, 3(43), 1-10.

Kamsani, Y. S., Rajikin, M. H., Khan, N. A. M. N., Satar, N. A., Chatterjee, A. (2013). Nicotine-induced cessation of embryonic development is reversed by $\gamma$-tocotrienol in mice. Medical Science Monitor Basic Research, 19, 87 92.

Ke, C., Hou, Y., Zhang, H., Yang, K., Wang, J., Guo, B., Li, K. (2015). Plasma metabolic profiles in women are menopause dependent. PLoS ONE, 10(11), $1-10$.

Khor, S. C., Wan Ngah, W. Z., Mohd Yusof, Y. A., Abdul Karim, N., Makpol, S. (2017). Tocotrienol-rich fraction ameliorates antioxidant defense mechanisms and improves replicative senescence-associated oxidative stress in human myoblasts. Oxidative Medicine and Cellular Longevity, 2017, 1-17.

Lawton, K. A., Berger, A., Mitchell, M., Milgram, K. E., Evans, A. M., Guo, L., Milburn, M. V. (2008). Analysis of the adult human plasma metabolome. Pharmacogenomics, 9(4), 383-397.

Liu, J., Liu, M., Ye, X., Liu, K., Huang, J., Wang, L., Ji, G., Liu, N., Tang, X., Baltz, J.M., Keefe D.L., Liu, L. (2012). Delay in oocyte aging in mice by the antioxidant N-acetyl-1-cysteine (NAC). Human Reproduction, 27(5), 1411-1420.

Mascarenhas, M. N., Flaxman, S. R., Boerma, T., Vanderpoel, S., Stevens, G. A. (2012). National, regional, and global trends in infertility prevalence since 1990: A systematic analysis of 277 health surveys. PLoS Medicine, 9(12), 1-12.

Mokhtar, N. M., Rajikin, M. H., Zakaria, Z. (2008). Role of tocotrienol-rich palm vitamin $\mathrm{E}$ on pregnancy and preimplantation embryos in nicotinetreated rats. Biomedical Research, 19(3), 181-184.

Nagy, A., Gertsenstein, M., Vintersten, K., Behringer, R. (2003). Manipulating the mouse embryo: A laboratory manual (Vol. 3). New York: Cold Spring Harbor Laboratory Press Cold Spring Harbor.

Nasibah, A., Rajikin, M. H., Nor-Ashikin, M. N. K., \& Nuraliza, A. S. (2012). Effects of tocotrienol supplementation on pregnancy outcome in mice subjected to maternal corticosterone administration. Journal of Oil Palm Research, 24, 1550-1558.

Norerlyda, H., Fathimah, M., As, N., Mara, U. T. (2015). The Effect of tocotrienol supplementation on plasma estradiol levels and quality of embryos in aging mice. Malaysian Journal of Microscopy, 38(11), 32-38.

Nur Azlina, M. F., Nafeeza, M. I. (2008). Tocotrienol and a-tocopherol reduce corticosterone and noradrenalin levels in rats exposed to restraint stress. Pharmazie, 63(12), 890-892.

Saidatul, A. K., Nasibah, A., Esa, N. Y., Nuraliza, A. (2014). Time-dependant effect of tocotrienol supplementation the quality of aging mouse embryo. Malaysian Journal of Microscopy, 10, 6-12.

Saleh, H. S., Omar, E., and Froemming, G. R. A. (2015). Tocotrienolpreseryes ovarian function in cyclophosphamide therapy. Human and Experimental Toxicology, 34(10), 946-952.

Sanderson, J. T. (2006). The steroid hormone biosynthesis pathway as a target for endocrine-disrupting chemicals. Toxicological Sciences, 94(1), 3-21.

Shahidee, Z. A., Effendi, I., Nasibah, A., Nuraliza, A. S. (2013). A timedependent study on the effect of corticosterone-induced DNA damage in mouse embryos. Acta Biologica Malaysiana, 2(2), 45-53.

Sukur, Y. E., Balik Kivancli, I., Ozmen, B. (2014). Ovarian aging and premature ovarian failure. Journal of the Turkish German Gynecological Association, 15(3), 190-196.

Xia, L., Zhao, X., Sun, Y., Hong, Y., Gao, Y., Hu, S. (2014). Metabolomic profiling of human follicular fluid from patients with repeated failure of in vitro fertilization using gas chromatography/mass spectrometry. International Journal of Clinical and Experimental Pathology, 7(10), 7220-7229.

Wu, L. L. Y., Dunning, K. R., Yang, X., Russell, D. L., Lane, M., Norman, R. J., Robker, R. L. (2010). High-fat diet causes lipotoxicity responses in cumulus - Oocyte complexes and decreased fertilization rates. Endocrinology, 151(11), 5438-5445. 